\title{
ADOPTING MEASURES TO REDUCE POWER OUTAGES
}

\author{
Abdullah M. Shaalan \\ Department of Electrical Engineering, King Saud University, \\ Riyadh, Kingdom of Saudi Arabia
}

\begin{abstract}
This work investigates and evaluates the electric energy interruptions to the residential sector resulting from severe power outages. The study results show that this sector will suffer tangible and intangible losses should these outages occur during specific times, seasons, and for prolonged durations. To reduce these power outages and hence mitigate their adverse consequences, the study proposes practical measures that can be adopted without compromising the consumers' needs, satisfaction, and convenience.
\end{abstract}

\section{KEYWORDS}

power outages, energy interruption, cost, residential consumer, energy conservation.

\section{INTRODUCTION}

Electric energy interruptions occur when the available system capacity, due to severe power outages, is insufficient to meet the consumer's loads requirements. These capacity deficits which lead to energy interruptions are particularly critical at sites where the environment and public safety are at risk. Institutions such as hospitals, sewage treatment plants, water reservoirs, airports, public places, etc., usually have backup power sources, such as standby generators, which will automatically start up when electric power is lost. Other critical systems, such as telecommunications and computer facilities are also required to have emergency power sources. Telephone exchange rooms usually have uninterrupted power supply (UPS) (arrays of lead-acid batteries) for backup and also a socket for connecting a generator during extended periods of outage. During these events of system deficits, interruptions costs will be borne by the electric company, its consumers and perhaps, by the entire society. The company interruptions costs include loss of revenues and increased expenses of repair and maintenance. The company costs usually form only a small part of the total interruptions costs while the greater part is that borne by its consumers.

The difficulty associated with estimating residential losses, resulting from severe power outages, is due to the fact that the activities pertaining to this sector are not productive and most of its outputs are consumed within the household premises and thereby cannot be valued in the market. Interruptions may interfere with housekeeping activities such as cooking, washing, vacuum cleaning, and disrupt the use of refrigerators, air conditioners, lighting, computers, game consoles, entertainment systems as well as negatively affect ceremonial gatherings and social events etc. More seriously, such disruptions may compromise the health of vulnerable individuals. Therefore, residential consumers may incur tangible losses such as foods spoilage and paying extra expenses and intangible losses in terms of inconvenience, discomfort, anxiety, and frustration.

DOI: 10.14810/elelij.2018.7201 
Electrical and Electronics Engineering: An International Journal (ELELIJ) Vol.7, No.1/2, May 2018

\section{REVIEW OF SOME EXISTING STUDIES}

In a study, conducted at an international level, Vivien et al [1] provided empirical data that tested the relationship between energy consumption and income per capita, at the household level. They determined that at high levels of net energy consumption, increasing gross energy consumption may cause power outages which can be avoided by switching to more efficient energy sources.

In their work, Kristina and Eto [2] discussed the massive electric power outage that occurred in the northeastern United States on August 14-15, 2003.They estimated the losses associated with that severe power outage affecting residential consumers for longer durations. They concluded that losses increased in a nonlinear manner with interruption duration.

Manikya et al [3] utilized a practical radial distribution system database in the development of an individual consumer sector and established a composite consumer damage function for a diverse class of consumers. The main objective of the paper is to assess reliability cost-worth indices of expected energy not served (EENS), expected cost of interruptions (ECOI), and interrupted energy assessment rate (IEAR) of a typical radial practical distribution system using a generalized analytical technique. The results presented in this paper can be useful for the electric power companies, designers, and planners in the decision-making process.

Layton [4] used a survey that evaluated how far households were "willing to pay" in order to avoid unexpected interruptions in electricity service. In this survey, the author used a statistical approach that was defined as a function of household characteristics, outage attributes, and outages history. He showed that losses estimation is sensitive to the interaction of attributes of previously experienced and hypothetical interruptions.

Snead [5] discussed the issue of energy efficiency and conservation in the residential sector and showed that energy efficiency can be targeted to reduce peak demand, leading to a significant fuel savings at a time when supply is constrained.

Benders [6] developed a web-based tool that addresses direct as well as indirect energy requirements. By means of a simple expert system, participants could attain options and feedback on energy reduction. This tool was tested in Groningen city (the Netherlands) with a sample of 300 households, resulting in a direct and indirect energy reduction of about $31 \%$ compared to total energy consumption.

Marshall [7] used energy-conservation programs that focused on the residential sector with more understanding on how the variables that affected household energy conservation lead to moreeffective consumer energy conservation. In this study, mail questionnaires were sent to 2000 Ventura County residents randomly selected from the Hayne's telephone directory. There were 500 returned questionnaires yielding a response rate of $25 \%$. Results indicated that home-owners adopted significantly more efficiency measures than renters. Respondents favored local energyconservation policies that required no personal action.

McMakin [8] described energy-conservation campaigns that were applied at two military installations where residents did not pay their own energy charges. Before-and-after energy use was measured and residents were surveyed about their energy consumption behaviors. Residents mentioned that they were motivated by the desire to do the right thing, set a good example for their children and have a comfortable home. These studies may have implications for other situations where residents are not charged for individual energy use, including other government-subsidized facilities, master-metered apartments, and hotels. 
Electrical and Electronics Engineering: An International Journal (ELELIJ) Vol.7, No.1/2, May 2018

Fuji [9] developed a model that explained household choice of electricity conservation modes. The model was based on the premise that households would adopt those conservation modes that yielded benefits greater than perceived costs. The author found that households differed in the conservation modes they adopted. High-income households were more likely to implement expenditure-intensive methods, while low-income households were more likely to adopt timeintensive conservation methodologies. The results suggested a possible explanation as to why high-income families and residents of single-detached homes saved the largest (absolute) amount of energy. A popular explanation was that these households consumed the most energy, and thus would be most likely to benefit.

Yoshiyuki [10] evaluated energy conservation methods for the residential sector by employing a model that simulated city-scale energy consumption within the residential sector by considering the diversity of household and building types. In this model, all the households in the city are classified into 380 categories based on the household and building type. The accuracy of the model is was verified by comparing its results with the statistical and the measured data on Osaka City, Japan. Various types of energy conservation measures planned by the Japanese government for the residential sector are simulated and their effects on Osaka City are evaluated quantitatively.

\section{WORK OBJECTIVES AND PROPOSED METHODOLOGY}

The review of the preceding studies reveals that their authors assessed the energy conservation in the residential sector without explicitly considering it as a hedge against power outages and a remedy to energy ceases. Hence, it is the Author's impression, that there was little attention given to the advantageous and rewarding correlation between coherent energy conservation and least outages occurrences. Therefore, the objective of this work is to narrow this gap in the present study. Therefore, the first step of this endeavor is to explore, from the consumer's perspective, the adverse effects of the energy interruptions that reflect enormous damages (tangible and intangible) to the residential sector in the city of Riyadh. The second step is to propose, analyze, and employ energy conservation strategies that lead to both energy conservation and costs saving. To fulfill these two essential steps, the following processes have been established:

A consumer survey has been used to achieve practical and definite results that can estimate the real impact of energy shortages upon the residential sector. It is the author's opinion that the most suitable estimation of outages occurrences and their impacts is the consumer's own assessment. Based on his personal perception to negative consequences during power outages and his level of preparedness or willingness-to-pay, he may go to great lengths to avoid such outages or, at least, mitigate their effects. This approach is theoretically more pertinent to the perception of the residential consumer and his needs.

\section{COST ESTIMATION BASED ON CONSUMER'S PERCEPTION}

Most outages effects that are discussed in many of the published works are intangible and cannot be assessed in terms of monetary values. The appropriate question to ask, therefore, is: "What set of preparations and precautions should a residential consumer adopt as a criterion to ensure both supply adequacy, continuity and quality worth? The answer depends on practical and theoretical structure of the analyses. In general, it is the author's opinion that one of the most suitable estimation of reliability worth is the consumer's preparatory actions during outages and his willingness-to-pay to avert their adverse impacts. This approach is practically sound and more 
Electrical and Electronics Engineering: An International Journal (ELELIJ) Vol.7, No.1/2, May 2018

related to the perception of the residential consumer and to his energy requirements. Therefore, in order to seek the consumer's readiness and the types of preparatory actions he intends to undertake against possible power outages and energy interruptions, respondents are directed to imagine a hypothetical situation where their local electric company announces unexpected power outages that will occur daily during Summer time for various durations. They are then asked to predict which action(s) they might take in preparation for the outages. The costs quoted in the list of actions are used to estimate the cost of preparations that respondents indicate that they are willing to undertake to eliminate or mitigate the contrary effects of the outages. Also, the survey aims to explore the extent to which they are willing to pay to avert service cessation. Therefore, it is suggested that the power system has become subject to more frequent power outages. To increase system reliability, the company may add generating units and/or reinforce its network facilities which may result in tariff increase. Hence, the question postulates daily power outages during the Summer period for durations of 20 minutes, 1 hour, 4 hours, and 8 hours. A range of possible tariff rate increases is proposed, and the consumers are asked to perceive and appraise the possible damage resulting from service interruptions and consequently discern appropriate tariff rate increases based on its prevailing present structure. The data reported by the respondents is exhibited by Figure 1. The survey results show that a significant number of respondents are willing to pay a higher rate for even up to $20 \%$ above the cost of the normal charge to avert prolonged outage durations. The willingness-to-pay, however, becomes less when more rate increase is suggested, or less frequent outages are proposed. The costs per $\mathrm{kWh}$ lost for various durations estimated, as shown in Figure 1, is probably the most credible and meaningful for the residential sector, in comparison with other studies and for planning purposes.

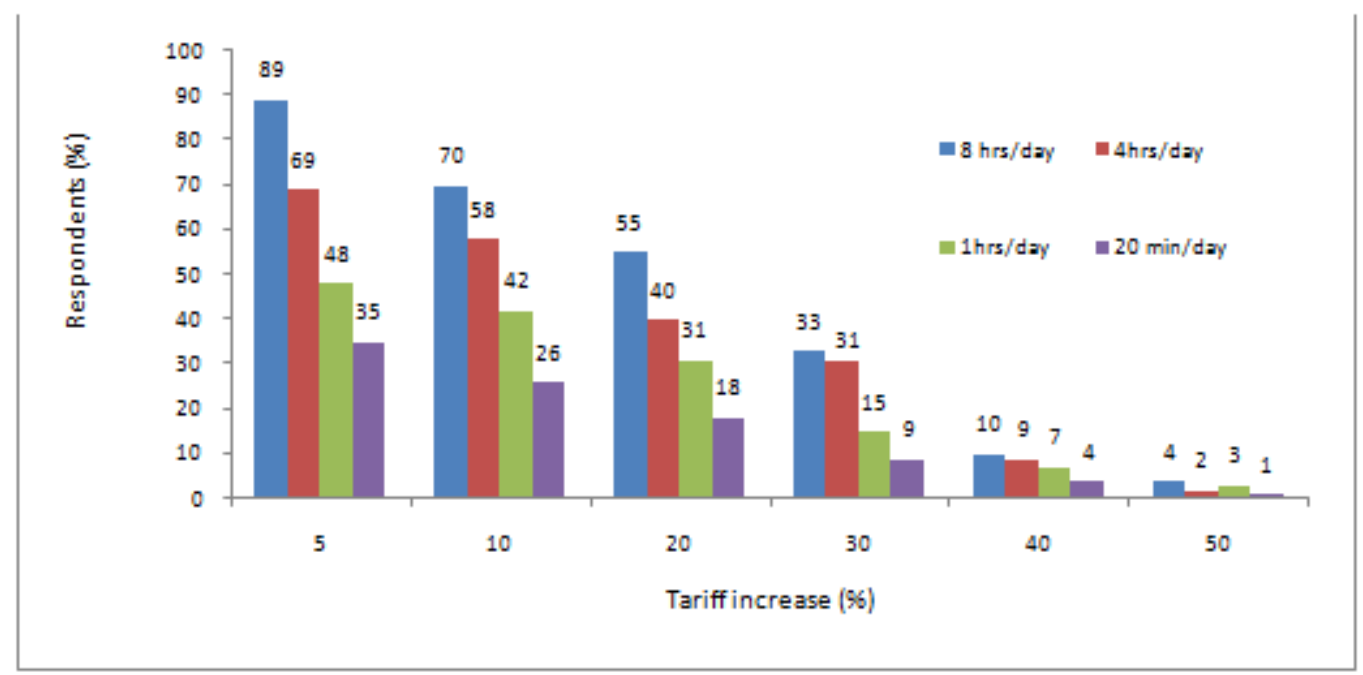

Figure1. Suggested tariff rate increase with outage durations

\section{DEVELOPED MATHEMATICAL MODEL}

In general, the most important household outputs that consume electricity are housekeeping duties, nutrition supplies, and social activities. These outputs are domestic activities that are consumed within the household premises and their losses costs due to outages cannot be straightforward or easily assessed in terms of monetary values. In the following analysis, a method to reduce these losses costs will be established through an energy conservation mathematical model. 
Electrical and Electronics Engineering: An International Journal (ELELIJ) Vol.7, No.1/2, May 2018

Now, let the set representing electricity service is defined by the varying load, L for each individual consumer $\mathrm{j}$ in a dwelling type $\mathrm{i}$ as follows:

$$
L=L_{j i} j=1 \text { to } m \text { and } i=1 \text { to } n
$$

The load is a function of other variables and the equation may be written as:

$$
L_{j i}=L_{j i}\left(P_{j i} \cdot Y_{j i} \cdot O_{j i}\right)
$$

Where $\mathrm{P}$ is the type of electrical appliance, $\mathrm{Y}$ represents the intensity of energy utilization (domestic activities), and $\mathrm{O}$ is an unexpected outage(s) occurrences that may affect the load levels. The energy cost (invoice charge), that the consumer $j$ of dwelling type $i$ pays in regular intervals (T), set by the local electric company, as a consequence of providing the electric service, can be denoted as an Energy $\operatorname{Cost}\left(\mathrm{EC}_{\mathrm{ji}}\right)$ and expressed as:

$$
E C_{j i}=E C_{j i}\left(L_{j i} \cdot T_{j i}\right)
$$

As described in Equation (2), the cost incurred by the residential consumers because of power outages resulting in energy interruptions may be represented as a function of outage size as well as its lasting duration. For the same category, the outage(s) cost designated as $O C_{j i}$ can be expressed as:

$$
O C_{j i}=O C_{j i}\left(O_{j i} \cdot T_{j i}\right)
$$

The energy cost (EC) described in Equation (2) corresponds to such charges (USD/kWh) paid to the utility (local electric company) for the energy delivered and consumed within the residential consumer property. The outage cost (OC) expressed in Equation (3) corresponds to the direct and indirect costs borne by the residential consumer for the kilowatt-hours not delivered because of power outages.

Now, the expressions displayed in both Equations (2) and (3) can be convolved to arrive at the most appropriate net benefit (NB) of electricity consumption that will ensure both service continuity and quality for a residential consumer as follows:

$$
N B_{j i}=\sum_{j=1}^{m}\left[\sum_{i=1}^{n}\left(T B_{j i}-O C_{j i}\right)-E C_{j i}\right]
$$

Where $T B_{j i}=T B_{j i}\left(L_{j i}\right)$ is the total benefit of energy consumption in the absence of outages. It is obviously realized from Equation (4) that the consumer will gain a benefit in terms of decreasing his electricity bill and avoiding the costly outages if he utilizes and conserves his energy consumption properly and wisely. The residential sector is urged to adopt specific programs and abide by certain rules for energy conservation (for example, choosing the efficient air conditioners, applying roof and wall insulation, using the energy saver types of lamps, using double-glaze and shaded windows, utilizing the sky light and solar energy, etc.). The change in the net benefit (NB) due to change in consumer behaviour to enhance his energy conservation (i.e. variation in the set of load levels), yields the following equation:

$$
\Delta N B^{l}=N B^{l+1}-N B^{l}
$$

By using Equations (2-4) into Equation (5), the resultant change in net benefit $\Delta N B^{l}$ is given by: 
Electrical and Electronics Engineering: An International Journal (ELELIJ) Vol.7, No.1/2, May 2018

$$
\Delta N B^{l}=\sum_{j=1}^{m} \sum_{i=1}^{n}\left[\frac{\partial}{\partial L_{j i}}\left(T B_{j i}-O C_{j i}^{l}\right) \cdot \Delta L_{j i}^{l}-\frac{\partial C E_{j i}^{l}}{\partial L_{j i}} \cdot \Delta L_{j i}^{l}\right]
$$

On the basis of the foregoing discussion, a simplified version of Equation (6) can be expressed as:

$$
\Delta N B^{l}=-\Delta O C^{l}-\Delta C E^{l}
$$

where,

$$
\Delta O C^{l}=\sum_{j=1}^{m} \sum_{i=1}^{n}\left[\left(\partial O C_{j i}^{l} / \partial L_{j i}^{l}\right) \cdot \Delta L_{j i}^{l}\right]
$$

and,

$$
\Delta C E^{l}=\sum_{j=1}^{m} \sum_{i=1}^{n}\left[\left(\partial C E_{j i}^{l} / \partial L_{j i}^{l}\right) \cdot \Delta L_{j i}^{l}\right]
$$

In Equation (7), it is assumed that:

$$
\left|\Delta N B^{i}\right|=\left|\Delta O C^{i}\right|-\left|\Delta C E^{l}\right|
$$

To interpret Equations (6) and (8) above, that the energy interruptions and excessive energy consumption can be envisaged as a coherent correlation. This correlation can be utilized in attempting to reduce power outages by embracing and applying effective and practical energy conservation measures that can reduce the occurrences of these outages and allow the consumer to fulfil his domestic duties, enjoy leisure times, and practice social and ceremonial activities.

For Equation (8), it could be stated that: "the customer can maximize his net benefits of energy consumption up to the prescribed load level designated as $\mathrm{L}^{*}$ where exceeding this limit may cause power outages and hence energy curtailment". [See Figure 2]

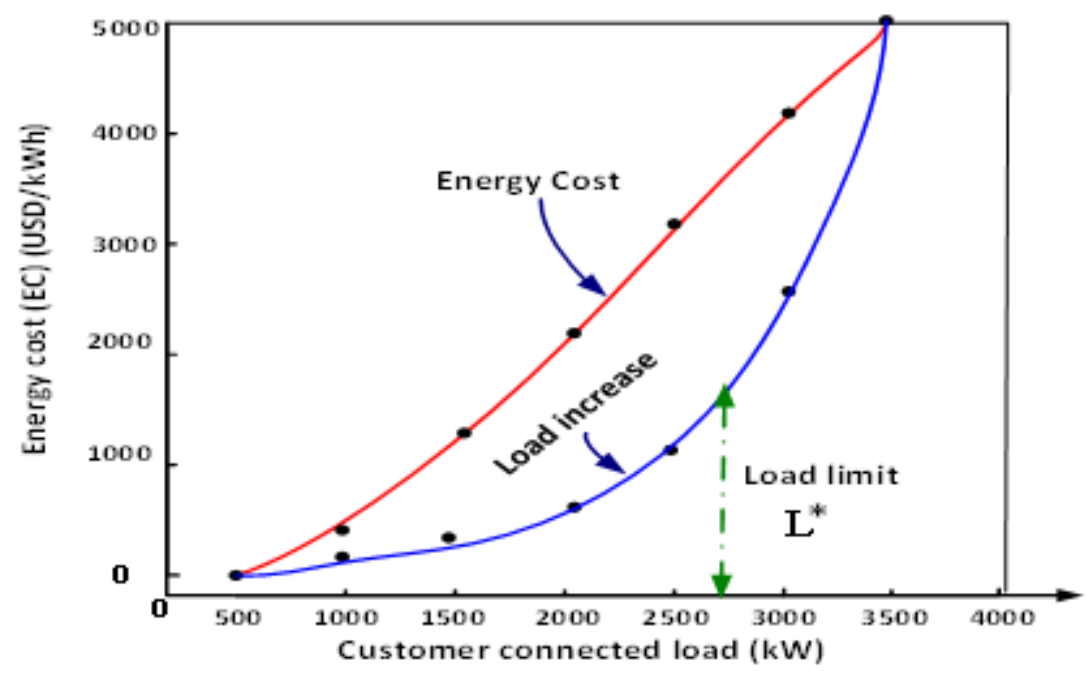

Figure 2. Limits between Energy consumption cost and outage cost 
Electrical and Electronics Engineering: An International Journal (ELELIJ) Vol.7, No.1/2, May 2018

\section{OUTAgE COST ESTIMATION BY USING SURVEY AND MATHEMATI- CAL APPROACHES}

In this research, two main approaches were considered and presented. An obvious approach is a rate increase approach, wherein respondents were asked to what extent in tariff rate increase are they are willing-to-pay to avoid outages for various outages durations. The direct worth evaluation approach asked consumers to place a monetary value on the effects of certain interruptions scenarios or to assess the worth to them of not having to experience an interruption. The average value of the maximum amount per month that the respondents were willing to pay for less severe outages (interruptions) occurrences is based on their average monthly energy consumptions $(\mathrm{kWh} / \mathrm{mo}$.) and invoice payments (USD/mo.) during Summer season. This approach may suffer due to the difficulty that residential respondents encounter when attempting to give a meaningful answer to direct evaluation questions. This model can decrease the size of the problem that may be associated with consumer lack of experience in rating the worth of service adequacy and continuity. Estimates results of both approaches are shown in Table 1 and plotted in Figure 3 for comparison. The curves show some discrepancy which may be attributed, in the questionnaires results, to the infrequent outages occurrences and subsequent lack of enthusiasm on the part of consumers to respond to outages in buying emergency items or taking any precautionary actions. The model estimates seem to be higher and this also could be ascribed to the electricitydependence weight embodied in the estimate due to the link between the use of energy and the per capita income. Both curves demonstrate clearly the time-dependent and the non-linear nature of the outages cost that probably may reach prohibitive limits should outages lasted and extended for longer durations.

Table 1. Variation of outages cost with outage duration

\begin{tabular}{|c|c|c|c|}
\hline \multirow{2}{*}{ Outage durations } & \multicolumn{3}{|c|}{ Outages Cost (USD/kWh) } \\
\cline { 2 - 4 } & Survey estimate & Model estimate & Predicted estimate \\
\hline 20 min. & 0.23 & 0.34 & 0.28 \\
\hline 1 hour & 0.52 & 1.24 & 0.69 \\
\hline 4 hours & 4.00 & 10.41 & 0.71 \\
\hline 8 hours & 99.80 & 140.10 & 121.43 \\
\hline
\end{tabular}

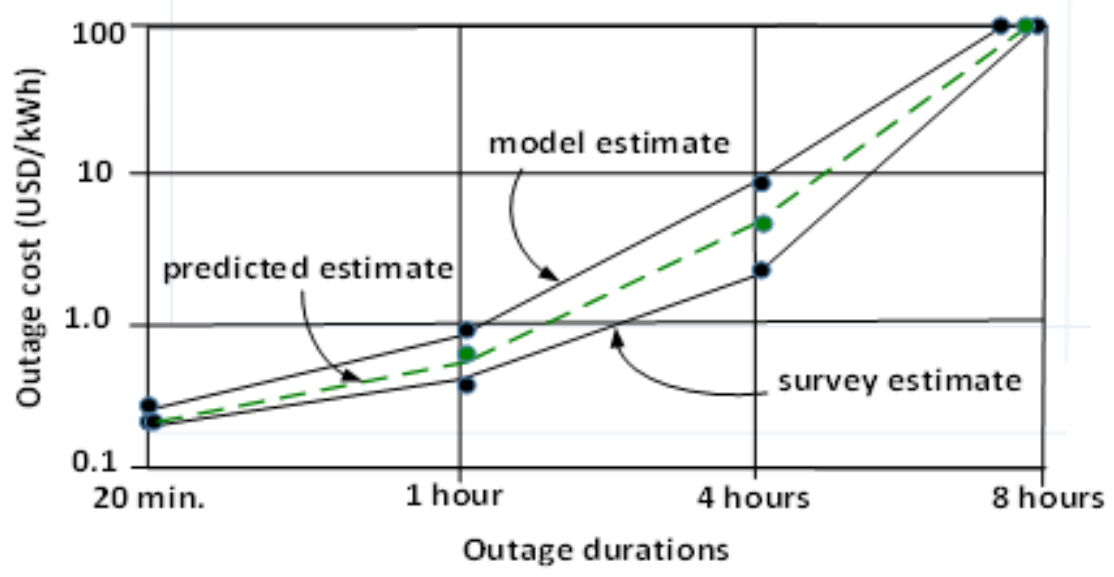

Figure 3. Variation of outage cost vs. outage durations 
Electrical and Electronics Engineering: An International Journal (ELELIJ) Vol.7, No.1/2, May 2018

\section{CONCLUSIONS}

This work presented results of a study conducted to assess the perceived losses and costs incurred by the residential sector in the city of Riyadh due to severe electric power outages that result in energy curtailments. It has focused on the implementation and utilization of practical and theoretical tools for evaluating an essential factor for reducing power outages and energy interruptions based on explicit consideration of consumer perception and evaluation to the interruptions impacts and consequences. The results reveal that these outages will deprive consumers from the usage of certain essential appliances, hinder domestic activities, hamper social ceremonies and events, cause food spoilage, and adversely impact the health of vulnerable individuals. Two approaches, based on the consumer's willingness-to-pay to avert these outages, have been developed to estimate the consumer's perceived costs should outages occur in specific periods and last for longer durations. The estimates obtained for the costs imply a time-dependent non-linear outage cost. One major contribution of this paper is manifested in the development of useful tools for system planners that enable them to incorporate consumer perceptions and preferences that can be used as a key input to energy conservation, tariff structure, and reliabilitycost evaluation in power system planning process.

\section{REFERENCES}

[1] Vivien, F., Jean, P, and Woodon, Q.,(2000) "Energy consumption and income: An inverted-U at the household level", World Bank.

[2] Kristina, H. and Eto, J., (2004) "Understanding the cost of power interruptions to electricity consumers. "Ernest Orlando National Laboratory, University of California Berkeley.

[3] Manikya, R., Prasad, P. and Tulasi, R., (2010) "Consumer outage cost evaluation in electric power systems", Journal of Engineering and Applied Sciences, Asian Research Publishing Network(ARPN), India, Vol. 5, No. 8.

[4] Layton, D. (2006) "The cost of power interruptions to the residential consumers." School of Public Affair, University of Washington, Applications of Simulation Methods in Environmental and Resource Economics.

[5] Snead, B., (2006) "Energy efficiency and conservation in the residential, commercial and industrial sectors", Final Report, Kansas State University, USA.

[6] Benders, R., (2006) "New approaches for household energy conservation: In search of personal household energy budgets and energy reduction options", Energy Policy, Volume 34, Issue 18,PP. 3612-3622.

[7] Marshall, M., (1987) "Socialpsychological correlation of domestic energyconservation activities", Thesis (Ph. D.), Claremont Graduate School, CA (USA).

[8] McMakin, A., (2002) "Motivating residents to conserve energy without financial incentives", Environment and Behavior Journal, USA.

[9] Fuji, E. T., (1989) "Model of household electricity conservation behavior", Land Econ. ; Vol./ Issue: 60:4. 
Electrical and Electronics Engineering: An International Journal (ELELIJ) Vol.7, No.1/2, May 2018

[10] Shimoda Yoshiyuki, Asahi Takahiro, TaniguchiAyakoet and Mizuno, Minorual, (2007) "Evaluation of city-scale impact of residential energy conservation measures using the detailed end-use simulation model", Energy, Volume 32, Issue 9, PP. 1617-1633.

\section{AUTHOR}

\section{Abdullah M. Shaalan}

Joined the college of engineering, King University since receiving his doctorate in electrical engineering from the University of Manchester (UK) in 1985. His specialization and research of interests fall within the areas of power system planning, reliability evaluation, electrical safety, environment protection, load management and energy conservation. He participated in many local, regional and international technical and scientific committees, seminars, conferences and workshops. He offered consultancy services to many governmental and private entities in his specialization areas. He is an active member in many scientific societies and academic affiliations.

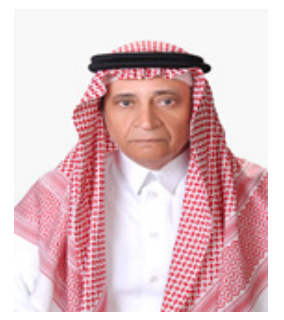
$\mathrm{He}$ authored and translated books in various fields of electrical engineering as well as wrote articles for public awareness in the safety of electrical installations and energy conservation. Obtained a lot of prizes, trophies and certificates of appreciation for his vast contributions and activities aimed to develop and improve the performance of several electricity sectors. Also, supervised many MSc and PhD dissertations and theses. Also, conducted many funded projects for local and foreign agencies. He is currently working as the supervisor of the "Zamil Industrial Group Chair for Electricity Conservation" at the College of Engineering, King Saud University, Riyadh, Kingdom of Saudi Arabia. Also working as a part-time consultant at the Saudi Arabian Standards Organization (SASO) since 1995 until now. 